\title{
LIBRO
}

Álvaro Vargas Llosa: Liberty for Latin America

(New York: Farrar, Strauss and Giroux, 2005)

\section{SOBRE EL LIBERALISMO Y EL ATRASO DE AMÉRICA LATINA}

\author{
Manuel Mora y Araujo
}

\section{Liberty for Latin America es una nueva y valiosa contribución en} la línea de ensayos que defienden las ideas liberales y su pertinencia para las naciones latinoamericanas. El eje del libro es un análisis de las causas del fracaso económico de las sociedades de nuestro continente. En la era del capitalismo exitoso, en un período en que han tenido lugar los más notables procesos de desarrollo económico de la humanidad, América Latina continúa rezagada. Más allá de las disparidades entre las naciones de la región, ninguna de ellas se cuenta entre las que crecieron a tasas más altas en el mundo durante las últimas décadas y varias están entre las que crecieron menos. Álvaro Vargas Llosa busca explicar esta situación en términos de la falta de libertad —económica, pero no sólo económica — en América Latina.

Un libro ambicioso y denso como éste puede perseguir diferentes propósitos o, independientemente de los motivos del autor para escribirlo, despertar intereses distintos en distintos públicos. En primer lugar se ofrece

Manuel Mora y Araujo. Sociólogo y está dedicado a la investigación social y de opinión pública, la consultoría comunicacional y el análisis político. Actualmente es presidente del Consejo de Dirección de la Universidad Torcuato Di Tella en Buenos Aires y ejerce la docencia universitaria. Ha publicado diversos libros sobre temas de su especialidad, entre ellos El Voto Peronista; Ensayo y Error; La Argentina: Una Víctima de Sí Misma; y El Poder de la Conversación: Elementos para una Teoría de la Opinión Pública. 
como una fuente de información, la que es de por sí valiosa y estimulante. En segundo lugar constituye una presentación muy articulada de argumentos que seguramente respaldarán o reforzarán las convicciones de personas que ya comparten en lo general las ideas del autor. Los públicos de ideas que ya están constituidos son demandantes de obras que alimentan sus convicciones, las refuerzan, las enriquecen, les proporcionan argumentos para el debate con quienes piensan de otro modo o promueven discusiones de aspectos específicos dentro de un marco de ideas común. En tercer lugar, hay una posible función persuasiva: llegar a otros públicos, introducir ideas nuevas en mentes estructuradas con otras ideas.

Desde la perspectiva de la propagación de una visión del mundo que está lejos de ser ampliamente compartida en el planeta, la tercera función me parece importante. Personalmente me siento atraído por ella. No tengo manera de establecer cuál será el impacto de Liberty for Latin America en el mercado, en términos de estos distintos núcleos de intereses intelectuales o de otras segmentaciones del mismo. Me parece que el libro de Vargas Llosa, por la forma en que está articulado, por la manera en que desarrolla su hilo conductor, puede resultar atractivo a quienes comparten los interrogantes iniciales y el planteo del problema pero pueden no compartir los argumentos del autor; pero a la vez no es demasiado condescendiente con quienes piensan de otro modo. Este artículo comentando el libro está hecho con un ojo puesto en ese hipotético público que podría estar predispuesto a exponerse a obras sin compartir a priori las ideas que exponen.

Muchos de los argumentos desarrollados en libros como Liberty for Latin America pueden encerrar la implicación de que sólo una utopía liberal podría proporcionar la orientación para la acción capaz de modificar de raíz este orden insatisfactorio en el que vivimos. Esa conclusión contiene el peligro de la semilla autoritaria que anida siempre en toda utopía - incluyendo la liberal—. Rescato de este libro que no parece sugerir ese camino, sino más bien un camino gradual por el que se pueda concebir un cambio de la realidad más incremental.

\section{El argumento central}

La tesis inicial de Vargas Llosa es que a lo largo de su historia, los pueblos latinoamericanos han sufrido el peso de factores opresivos sobre la libertad de los individuos — corporativismo, mercantilismo, privilegios, transferencias de riqueza y leyes con fundamento político-. El análisis busca mostrar que a pesar de los cambios políticos y sociales seculares, 
esos factores continúan vigentes en sus rasgos esenciales, aunque adopten distintas formas. El argumento me parece persuasivo en lo que hace a la evolución latinoamericana. Me siento menos persuadido cuando trato de comprender en qué medida y por qué esos factores dejaron de operar, después de haber mantenido igual vigencia, en sociedades que hoy funcionan con los principios del capitalismo de mercado.

El programa que propone Vargas Llosa desde la introducción a Liberty for Latin America es analizar estos fenómenos a la luz de dos principales dimensiones explicativas: las instituciones y la cultura, a las que agrega de manera implícita una tercera dimensión no menos importante: las ideas.

La relación entre las tres dimensiones podría dar lugar a disquisiciones teóricas y empíricas tan largas como este libro. De hecho, definir y desarrollar los conceptos relativos a cada una de ellas podría demandar un libro entero. Vargas Llosa no especifica en detalle cuáles son los atributos propios de cada dimensión, los que en teoría dan lugar a la emergencia de economías capitalistas vigorosas, pero sus conceptos de cada una son, no obstante, suficientemente claros. El peso de las instituciones es una premisa básica del autor; los factores del desarrollo capitalista en Europa y los Estados Unidos son ellos mismos "los síntomas y las consecuencias de marcos institucionales" sin los cuales "la inversión y el comercio no hubieran llevado a naciones enteras al capitalismo liberal". La relación entre las instituciones y la cultura queda establecida por boca de Giambattista Vico: "A cada estadio del cambio social corresponde un tipo propio de ley, gobierno, religión, arte, mito, lenguaje, costumbres”. La posibilidad de un desajuste entre las instituciones y la cultura no es explorada. Menos aun queda claro si las ideas mantienen alguna relación tan bien establecida con las otras dos dimensiones. De tal manera, si para simplificar las cosas tomamos cada una de las tres dimensiones en forma dicotómica y establecemos de ese modo ocho posibilidades, no hay en el libro un planteo exhaustivo de lo que ocurriría en cada una de ellas con el desarrollo capitalista. Más específicamente, me pregunto si puede pensarse que las buenas ideas bastarían para compensar, por ejemplo, un desajuste desfavorable entre instituciones y cultura, o si las malas ideas podrían descompensar la situación óptima de buenas instituciones y buena cultura. El punto no es menor; tal vez en esas combinaciones desviadas de los postulados teóricos residan algunas claves del fracaso de por lo menos algunos países de América Latina.

Por ejemplo, la Argentina se dio a sí misma instituciones bastante correctas en la segunda mitad del siglo XIX. Acogió igualmente las ideas correctas, provenientes de Europa y bien adaptadas por la intelligentzia 
local. Es posible, sin embargo, que la cultura, mezcla de la tradición anticapitalista hispánica y el impacto de las migraciones del sur de Europa, no maduró adecuadamente, y eso bien podría explicar el posterior fracaso argentino, incluyendo el deterioro de las instituciones. Presumo que Vargas Llosa razona en esa línea, pero no lo hace explícitamente.

El libro puede ser discutido en tres planos: (a) el de los hechos históricos, (b) el de las ideas, (c) el político. A continuación paso a referirme a los tres planos. No soy historiador sino un sociólogo generalista, por lo que me detendré más en discutir las ideas y el enfoque del análisis político de Vargas Llosa que su recapitulación de los hechos pasados.

\section{La historia}

En el plano de los hechos históricos, el libro ofrece una visión de los procesos sociales seculares de las sociedades latinoamericanas, desde la conquista hasta nuestros días. Es una visión a vuelo de altura; como tal debe ser juzgada. Sus menos de 300 páginas abarcan demasiado, pero no obstante cumplen su propósito. Desde esta perspectiva, sin duda esas páginas serán leídas con distinto interés por quienes buscan más bien una sucinta visión histórica comparativa de América Latina que por quienes están más interesados en la aplicación de las ideas de Vargas Llosa a la comprensión del pasado y el presente de América Latina.

No es un logro menor alcanzar una visión de los rasgos distintivos de las sociedades y las economías latinoamericanas desde las ideas liberales. Lo juzgo valioso porque coloca bajo una misma perspectiva los procesos históricos que con el tiempo adquirieron matices muy diversos en distintos países, más allá de que sus mismos orígenes no fueron todos iguales. Rescatar los elementos comunes a veces resulta molesto para historiadores orientados hacia un particularismo que busca la riqueza en lo singular de cada circunstancia; sin embargo, la generalización es útil y es un momento necesario en la búsqueda de una comprensión conceptual de lo que ocurrió y de lo que se propone que ocurra en el futuro.

\section{Las ideas}

Liberty for Latin America no se propone desarrollar de manera sistemática un paradigma liberal. De hecho, ninguna referencia a exponentes relevantes de esas ideas — clásicos o modernos— supera el par de referen- 
cias a lo largo de sus páginas. El paradigma entra como premisa de sus argumentos; pero es tan central a ellos que me parece justifica un análisis de sus proposiciones

En este plano, este libro es un aporte interesante a las ideas del liberalismo libertario moderado de nuestro tiempo. Encuentro interesante precisamente que esta versión del liberalismo libertario contiene diversos elementos de moderación — tal vez tan moderados que muchos libertarios extremos pueden no sentirse enteramente cómodos con ella- Los rasgos distintivos de lo que llamo 'liberalismo libertario' son: la desconfianza en la capacidad del estado de optimizar mejor que los intercambios espontáneos; el rechazo a toda forma de privilegios privados sustentados en factores de poder económico, sean estos ventajas monopólicas, favoritismo político o uso abusivo de recursos de poder; la defensa irrestricta de la libertad de elección en la esfera íntima de la vida de cada uno y en áreas públicas como la educación, y el reclamo de que la libertad individual se aplique a todos los órdenes de la vida y no sólo a algunos —algunos que, para los liberales económicos, suelen ser los derechos de propiedad, y para los liberales políticos los derechos y las libertades cívicas-. En un mundo capitalista en el que conviven mercados ampliamente desregulados con nichos sostenidos mediante la asignación de privilegios, protecciones y ventajas oligopólicas, tan sometido a regulaciones que vulneran derechos de propiedad sobre los bienes y el patrimonio y establecen restricciones a la libre circulación de las personas y de los recursos económicos, a la libertad de comportamientos privados, sexuales o íntimos, a la libertad de conciencia, y tantas otras, el liberalismo libertario sigue siendo una señal luminosa en la constelación de las ideas liberales de nuestro tiempo.

Por otra parte, las ideas libertarias de Vargas Llosa en varios aspectos son moderadas. Uno de ellos es la reivindicación del ámbito de la política en la visión liberal de las sociedades complejas: "la economía es acción humana bajo un conjunto de reglas, y las reglas, buenas o malas, son un material de la política”. Esta visión contrasta con la del liberalismo puramente económico, que subordina la importancia de la libertad política, y con la libertaria extrema, que concibe un mundo donde la política es simplemente irrelevante. El segundo aspecto moderado es la valoración positiva —reiterada a lo largo del libro- de lo que en el siglo XX dio en llamarse el ‘capitalismo popular', la posibilidad de una distribución con tendencia igualitaria de los bienes de capital. Esta preocupación lo vincula al liberalismo “social de mercado”, que se desarrolló en la Europa continental a partir de la II Guerra Mundial, pero se aleja de los ingredientes corporativistas y estatistas que en Europa con frecuencia estuvieron asociados a él. Y se contra- 
pone al liberalismo económico de raíz anglosajona, que puede ver ese tipo de perfil distributivo como una consecuencia posible de los procesos económicos desarrollados en mercados sin interferencias políticas pero no lo considera un valor prioritario. El enfoque crítico de la ola de privatizaciones de las últimas décadas es ilustrativo de la interesante visión del liberalismo por la que Vargas Llosa aboga.

Presumo que Vargas Llosa busca un debate de ideas con quienes no piensan como él. En esa dirección, pienso que en el debate de ideas de nuestra época el lado liberal no siempre se muestra preparado para un diálogo tolerante con ideas distintas - lo que atenta contra el propósito de la persuasión-. Por ejemplo, el hecho de que el antiguo ideal comunitarista adopte reiteradamente formas económicas colectivistas - la tradición jesuita en América Latina y su reencarnación en la utopía del Che Guevara o algunos sandinistas en Nicaragua, el comunitarismo de los kibutz en Israel, la actual reivindicación precolombina en Bolivia - justifica una comprensión que debe ir más allá de la mera adscripción a las categorías de 'correcto' e 'incorrecto'. Creo que en muchas épocas se ha manifestado una expectativa humana de un orden social capaz de generar vínculos (ligatures) que no ve una respuesta enteramente satisfactoria en el mercado, expectativa que a mi modo de ver requiere de los liberales una actitud receptiva, por no decir simpática. De hecho, como bien lo señala Vargas Llosa, los filósofos liberales clásicos son en alguna medida tributarios de tradiciones que valoran la cohesión social y las relaciones humanas amenazadas por el ejercicio del poder. El liberalismo y el comunitarismo tienen en común, en alguna medida, el punto de partida de la incompletitud del ser humano. La "mano invisible" que establece un orden espontáneo beneficioso para todos es una respuesta que divide las aguas, a partir del descubrimiento extraordinario de la lógica del mercado y de la división del trabajo; no hay duda que ese punto de partida merece una actitud abierta al debate ante otros desarrollos alternativos igualmente plausibles que se derivan de los clásicos. Vargas Llosa por momento lo advierte y, precisamente por eso, creo que esa línea de análisis merece más atención de la que recibe en este libro —y en general por parte de los pensadores liberales contemporáneos-.

La versión liberal capitalista, en su variante menos libertaria, ha reclamado fuertemente la vigencia de un estado que actúe como árbitro imparcial, con atribuciones administrativas que exceden en mucho la mera función judicial y el monopolio de la fuerza. Por el contrario, un comunitarismo más proclive a aceptar al mercado como espacio libre de interferencias estatales para los intercambios económicos y otros propios de la vida social - comunitarismo hoy en día poco frecuente pero no ausente por completo 
del mapa de la oferta de ideas - bien puede sentirse en parte tributario del ideal anarquista y defender de ese modo un orden con menos estado aun que el liberalismo capitalista, o una transferencia del poder del estado al ámbito territorial local donde las acciones del estado pueden más efectivamente reflejar consensos sociales inmediatos de lo que ocurre en el estadonación que ha sido propio de las sociedades capitalistas modernas.

Del mismo modo, pienso que el positivismo, tan influyente en América Latina desde la independencia y hasta entrado el siglo XX, desempeñó un papel importante en la superación de las ideas precapitalistas y tuvo puntos de contacto con las ideas liberales que se abrían paso al mismo tiempo que él y con las corrientes socialistas democráticas que en muchos casos contribuyeron a la aceptación de criterios liberales en medios sociales donde éstos difícilmente hubiesen nunca entrado por sí solos.

\section{La política}

En el plano del análisis político, la discusión queda abierta, pero en verdad Vargas Llosa apenas comienza a desarrollarla. En su visión, la política parece puro deber ser. Los gobiernos son juzgados con la vara normativa del autor (o del modelo normativo que se deriva de sus posiciones en el plano de las ideas), no en términos de las restricciones reales que encuentran los actores políticos en cada circunstancia. Las únicas restricciones que parecen existir en su perspectiva analítica son las que crean incentivos o propensiones a hacer lo incorrecto (por ejemplo, intereses corporativos o sectoriales, o sistemas de incentivos que promueven intereses particulares). Por qué nunca aparecen en el análisis las condiciones favorables a hacer lo correcto no me resulta claro, aunque me parece indudable que son esas condiciones las que podrían ayudarnos a entender los muchos casos de capitalismo de mercado exitosos en el mundo.

Cuando utilizo las expresiones ‘correcto’ e ‘incorrecto’, hablando de juzgar políticas públicas o propuestas de actores políticos concretos en circunstancias concretas, no estoy sugiriendo alguna crítica a ese tipo de juicios de valor. No me molesta particularmente que los hechos políticos sean analizados a partir de juicios de valor referidos a los resultados de las decisiones políticas. Y no mantengo diferencias importantes con el tipo de resultados, o de políticas, que interpreto que Vargas Llosa considera 'correctas' o 'incorrectas'. El mundo que me agrada se parece mucho al que le agrada a Vargas Llosa. Pero me produce alguna inquietud el déficit que encuentro en su análisis para explicar de qué depende, en cada circunstan- 
cia histórica, que las decisiones colectivas correctas sean adoptadas por los actores que se desempeñan en esas circunstancias.

Hasta donde lo veo, en el plano del análisis político Vargas Llosa concluye donde empieza: una discusión sobre la relación causal entre la dimensión institucional y la cultural. Una implicación de su análisis es que las sociedades latinoamericanas han sido mal dotadas en estos dos grandes factores del desarrollo de las naciones, de modo que toda posibilidad de cambio queda librada a la voluntad humana para torcer el rumbo que se genera desde ellos o a la capacidad intelectual de comprender qué es lo correcto; se admite que esos dos factores pueden ser modificados en algún punto del devenir de la historia, pero esto finalmente reposa en el voluntarismo. Cuánto respaldo político es necesario para que la voluntad de algunas personas o grupos sociales tenga posibilidades significativas de éxito no está claro; menos aun, de qué depende que ese respaldo eventualmente exista o sea generado.

Si en algunos lugares del planeta la humanidad ha tomado un rumbo más correcto, y si eso ha dependido de situaciones favorables en las instituciones y/o en la cultura, deberíamos entender qué ocurrió en esos lugares para que se generasen las condiciones favorables. No pienso - y me parece, revisando las páginas de este libro, que Vargas Llosa tampoco piensaque en el origen de los procesos históricos que produjeron las instituciones y los equilibrios culturales favorables al capitalismo de mercado hubo sólo buena voluntad o sólo prevalecieron las ideas correctas. Estoy inclinado a pensar que en las naciones donde se desarrolló un capitalismo exitoso se desarrollaron también condiciones políticas favorables, y que fueron esas condiciones, más que el voluntarismo de los actores, las causas de los mejores resultados. En muchísimos casos, las decisiones políticas que orientaron los procesos hacia el capitalismo liberal fueron adoptadas al costo de enormes conflictos; los ganadores, por así decirlo, seguramente exhibieron en cada caso voluntad e ideas adecuadas pero también capacidades políticas singulares. Las ideas favorables al capitalismo germinaron en un ambiente de ideas precapitalistas y se desarrollaron y articularon en los mismos lugares, en conflicto con éstas, y al mismo tiempo que otras ideas anticapitalistas modernas. Sin duda, esas ideas orientaron en muchos casos decisiones de gobierno, inspiraron a dirigentes públicos y privados y proporcionaron a las elites y a los sectores educados de las sociedades una visión intelectual del mundo y las bases para desarrollos del conocimiento histórico, económico y social que marcaron nuevos horizontes. Pero eso nunca fue suficiente; si el capitalismo se impuso no fue sólo porque sus ideas se demostraron superiores a otras sino más bien por la fuerza de los 
hechos. De la lectura de este libro me queda un interrogante sin respuesta acerca de lo que piensa Vargas Llosa al respecto.

En este punto, hay una pregunta importante: ¿es el cambio político un asunto que sólo concierne a las elites, a los grupos dirigentes de las sociedades? ¿Sólo la voluntad de los miembros de las elites cuenta? Por momentos, en partes del libro, Vargas Llosa parece sugerir esto; por momentos parece pensar que la voluntad de los ciudadanos comunes también pesa como factor causal. Ahora bien, si la voluntad de los comunes es una variable importante, ¿cómo concebir que puede producirse una voluntad de ir en pos del capitalismo liberal en esas personas?

No puedo prejuzgar acerca de la respuesta de Vargas Llosa a este interrogante. Muchos otros autores que trabajan en su misma línea de pensamiento, bajo el mismo paradigma de ideas, depositan casi toda su confianza en la capacidad de persuasión intelectual; tienden a desconfiar, y no pocos de ellos a desvalorizar, la comunicación política que, a falta de mejor término, y para diferenciarla de la comunicación de las ideas, propongo llamar 'estratégica'. Me explico. Una hipótesis, a la que por el momento adhiero, es que en las circunstancias históricas que hicieron posible que algunas sociedades se moviesen hacia el capitalismo de mercado con consenso social, eso ocurrió porque un inmenso número de personas comunes fueron persuadidas de elegir las opciones políticas que terminaron llevando por ese camino —elecciones que muchas veces ni siquiera fueron hechas bajo el supuesto de que ese sería el camino, o mucho menos bajo alguna idea precisa acerca de cuáles eran las opciones alternativas- A esto lo llamo comunicación estratégica. Otra hipótesis es que surgieron, en un inmenso número de personas, preferencias por moverse en esa dirección - en principio, hemos de pensar que facilitadas por un estado particularmente favorable de las instituciones y de la cultura- . A esto lo llamo la persuasión intelectual, el desarrollo, en las mentes de los actores políticos, de convicciones intelectualmente fundadas acerca de lo que es mejor o peor para sus sociedades.

Razonando bajo el supuesto de que las personas comunes cuentan, me resulta implausible que el diálogo intelectual sea productivo cuando uno de los interlocutores no es intelectual y no está interesado en ese diálogo. Y si la comunicación política, orientada a inducir a la gente a preferir lo correcto, no puede desenvolverse bajo códigos intelectuales, entonces sólo queda encontrar otros códigos o cruzar los dedos esperando que el cambio cultural haga lo suyo. Esos otros códigos son la comunicación estratégica.

Desde luego, las elites cuentan; lo que puede estar en discusión es si cuentan sólo ellas o si también cuentan los comunes. En esas napas de 
las sociedades conformadas por elites educadas y en mayor o menor medida consumidoras de ideas articuladas, la formación y las convicciones intelectuales son un factor. De hecho, tanto en el pasado más lejano como en las décadas más recientes, esfuerzos intelectuales volcados en una línea similar a la de Vargas Llosa rindieron sus frutos. A principios del siglo XIX, a finales de ese siglo, a mediados del siglo XX o en los años más recientes, la humanidad — y particularmente América Latina — asistió a la conversión intelectual de muchas personas de posiciones dirigentes que anteriormente abrevaban en vertientes de ideas completamente distintas y hasta opuestas.

Las ideas filosóficas y tecnocráticas restringen en buena medida el menú de opciones de los políticos; pero esas ideas siempre se presentan en ambientes donde otras ideas están en competencia, nunca son suficientes para excluir por completo la influencia sobre los políticos de demandas generadas en la sociedad. Por eso el esfuerzo de la persuasión es tan importante. Pero está claro que no basta. En un seminario en Rusia, hace pocos años, algunos de los economistas que implementaron las reformas liberales después de la caída del régimen soviético expusieron el programa que habían ejecutado y que acabó en un fracaso; cuando se les preguntó qué había salido mal, uno de ellos respondió: "en verdad, hicimos todo bien y salió todo mal, como siempre en Rusia”. Algo así ha pasado muchas veces en América Latina. La importancia de las ideas está clara, son necesarias; pero no bastan. Me parece que la respuesta de Vargas Llosa a esa situación es: "fracasan porque no han sido suficientemente consistentes". (Lástima que la historia no siempre ofrezca una nueva oportunidad.) Y queda, aun así, otro interrogante simétrico: a veces personas que no parecen haber cambiado mayormente sus propias ideas, tienen éxito en la dirección 'correcta'. Pienso que esto que llamo 'restricciones de la realidad' es un elemento que ayuda mucho a comprender la política.

En cualquier caso, para gobernar, los políticos — aun convertidosnecesitan de los comunes, deben recurrir a la comunicación política estratégica para persuadirlos y están igualmente sometidos a las restricciones del mundo real que aquellos que piensan de otro modo. La realidad me parece ser la resultante — siempre abierta, nunca determinada por completo- de distintas fuerzas que interactúan entre sí: coaliciones políticas y calidad de sus dirigentes, ideas en circulación, ideas e intereses predominantes en las elites, capacidad de éstas de influir en las preferencias de los comunes, capacidad de las elites económicas de influir en las decisiones de gobierno $\mathrm{y}$, desde luego, el contexto externo.

Parte del problema de América Latina, visto con ojos de un observador del presente, es que muchas personas comunes, muchísimas, no creen que el fracaso de las economías en las que viven y las miserias (materiales y 
morales) a las que están expuestas, se deben a que no se completó el camino de las reformas liberales; más bien piensan que la parte que se completó es la responsable, y por tanto favorecen o bien un paso atrás o bien un paso al costado ("ni tanto ni tan poco", como suele decirse coloquialmente —una fórmula que parece acabar siendo fatal para producir cambios-). Frecuentemente esas personas incorporan otros temas a su agenda. Por ejemplo, en algunos países resurgen olas de nacionalismo, como en Venezuela o en la Argentina; en otros, como en Perú o en Bolivia, aparecen reivindicaciones étnicas o geográficas, todos son asuntos relevantes en la identidad colectiva pero ajenos a la agenda liberal. Muchos cruceños en Bolivia se oponen a las nacionalizaciones de Evo Morales porque reclaman la autonomía de Santa Cruz y no ven con buenos ojos al estado centralista de su país, pero en verdad no son más favorables a una economía abierta que el gobierno de Morales.

Imaginemos la conjetura —que no hace mucho tiempo me hubiese sonado una fantasía surrealista, pero hoy no tanto- de que Alan García, Lula da Silva o Néstor Kirchner terminen dejando a sus países un poquito mejor encaminados hacia el 'camino correcto'. Por cierto, Vargas Llosa no se plantea tal hipótesis: esos gobernantes, aunque — como él admite— se muestran más sensibles a los riesgos de la inflación, del endeudamiento externo y del proteccionismo arancelario que años atrás, en última instancia confían incorregiblemente en el gasto público. Pero, si eso que conjeturo como improbable pero no imposible ocurriese, ¿̇a qué habremos de atribuirlo? No creo que podamos atribuirlo ni a las instituciones ni a la cultura que generaron a estos personajes de la política, ni a los factores que moldearon sus mentes con contenidos tan distintos a los del liberalismo de mercado. Imagino más bien que son 'restricciones políticas' —limitaciones en su espacio de acción, en las que se influyen recíprocamente intereses grupales diversos, algunos convergentes y otros divergentes, restricciones fiscales, financieras y económicas, factores internos y externos a cada país y tantos otros - las que los habrán llevado a actuar de una u otra manera. Vargas Llosa posiblemente dirá que tiene un mal pronóstico de esas situaciones (aun bajo la mejor de las hipótesis) porque serán tan inconsistentes como lo fueron muchos predecesores. También pienso que algunos de esos predecesores enfrentaron otro problema no previsto: que cuando la decisión política fue avanzar por el camino correcto, esos gobernantes convocaron a algunos expertos e intelectuales con las ideas correctas a contribuir a sus gobiernos, pero estos, aun con las ideas correctas, ignoraron la naturaleza de las restricciones políticas e imaginaron un mundo teóricamente despejado, cometiendo errores políticamente críticos. Y eso puede volver a ocurrir. 


\section{El liberalismo y el poder político}

En última instancia, quiero dejar planteado algo más que un desacuerdo o una duda. En el plano de las ideas tengo una reserva, tal vez la única relevante al comentar este libro. La tesis central de Vargas Llosa puede expresarse en estos términos: a más libertad, más prosperidad. Esa proposición no me parece contar con suficiente respaldo empírico, al menos para persuadir a las multitudes de personas comunes que aspiran a la prosperidad (para no hablar de las que tienen otras aspiraciones); tampoco para persuadir a personas más formadas intelectualmente. Para ponerlo en los términos del profesor Dani Rodick, de Harvard, en un reciente ensayo ${ }^{1}$, a largo plazo parece haber una correlación entre libertad y desarrollo económico; a corto plazo, en cualquier período, la correlación se diluye. (Basta pensar en las naciones que hoy exhiben las más altas tasas de crecimiento: algunas de ellas están entre las muy libres, otras en lugares intermedios entre la libertad y el colectivismo, y algunas entre las más totalitarias del mundo; y entre las que crecen poco se encuentra la misma diversidad. En nuestros días, el caso chino es superlativamente relevante al respecto.)

Por lo demás, la prosperidad puede ser descripta en términos de distintos parámetros: uno es el desarrollo de la economía — que habitualmente es medido como un promedio, cantidad de producto sobre número de habitantes—, otro es la dispersión alrededor del promedio —o desigualdad distributiva—, otro el número de personas por debajo de una línea discrecionalmente establecida como un mínimo nivel de vida aceptable en cada momento. No se deriva de las ideas liberales ningún orden de prelación normativa de estos parámetros. El capitalismo de mercado tiende a definirse por la prelación del promedio sobre la dispersión, la "economía social de mercado" supuestamente puso el acento en el equilibrio entre crecimiento e igualdad — con resultados dispares - y, a la larga, el capitalismo ha sido capaz de reducir el número de personas por debajo de la línea de pobreza — pero en forma despareja, ciertamente distinta en el centro y en la periferia de sus economías, y apelando a herramientas también muy diversas-.

Ahora bien, aun si fuera el caso que quedase evidenciada la ausencia de correlación entre libertad y prosperidad, sigue siendo válido aspirar a una mayor libertad. Éste es un valor de orden superior, una precondición de una calidad de vida y de desarrollo humano superior, y no es en absoluto claro que si debe elegirse entre políticas públicas que promueven el creci-

${ }^{1}$ Dani Rodrik, Arvind Subramanian, Francesco Trebbi: "Institutions Rule: The Primacy of Institutions over Geography and Integration in Economic Development”, octubre 2002. 
miento económico y la libertad, la preferencia ha de ir al crecimiento. Sostengo este punto de vista con la más íntima y profunda convicción, pero soy consciente de que contiene enormes dificultades políticas. Presumo que Vargas Llosa ha de compartir este juicio pero no estoy seguro, porque todo su análisis en este libro se apoya en la premisa de que con más libertad habrá más prosperidad y con menos libertad menos prosperidad, y no está claro qué debería preferirse si se plantea una disyuntiva crítica entre ambos términos, ni mucho menos qué hacer si a una mayoría de las personas comunes la prosperidad les resultase más atractiva que la libertad.

De aquí extraigo una conclusión personal. No creo que sea un camino conducente al cambio defender la libertad en términos políticos. La política es el reino del poder, y el poder y la libertad no son valores demasiado afines. El poder contamina; cerca de él la libertad pierde su encanto como valor de orden superior. Los sistemas políticos se construyen con comunicación estratégica más que con ideas; las decisiones de gobierno se adoptan con criterios muy diversos, entre ellos el sentido común — que muchas veces, pero no siempre- coincide con criterios liberales. Por lo tanto, es preferible encarar la política con enfoques estratégicos y cultivar las ideas en sí mismas, desarrollando su capacidad seductora y persuasiva con argumentos y con creatividad intelectual renovados. A veces, hasta algunos dirigentes políticos se dejan persuadir, ya lo sabemos; pero aun cuando ese no sea el caso, las circunstancias pueden llevarlos a actuar correctamente si un número suficiente de demandas políticas particulares se interpone en su camino. El camino del cambio pasa por esas demandas antes que por la mera voluntad de los dirigentes políticos.

Cuando el liberalismo se hace ideología política, al menos en los tiempos corrientes ha sufrido más problemas que beneficios. Se tornó un blanco visible y fácil, culpable de fracasos de no liberales tanto como de los supuestamente propios. Los esfuerzos por tomar distancia de tales fracasos habitualmente son vanos. Pienso que la defensa del liberalismo debe darse en tres planos diferenciados: el de la economía, el político y el de los valores. El liberalismo siempre aspiró a un orden social de igualdad ante la ley y ausencia de privilegios particulares.

El liberalismo contemporáneo en los hechos se ve enredado con frecuencia por los hilos de los políticos que buscan el poder del estado - a veces en nombre de las ideas liberales- y también por los hilos de los empresarios que buscan proteccionismo -no pocas veces, haciendo uso de una retórica liberal—. Para mucha gente, muy honestamente, el liberalismo económico huele a privilegio; los liberales deben sentirse llamados a un 
diálogo franco y tolerante con esa gente, comprendiendo sus motivos — que no son tan fácilmente desestimables-.

En el plano político el liberalismo no debería encontrar objeción alguna a la defensa irrestricta de las libertades públicas. Sin embargo, no ha sido fácil para el liberalismo posicionarse en las décadas recientes ante regímenes políticos militares que proponían un gobierno "limitado” pero autoritario (Chile bajo Pinochet es paradigmático al respecto). El debate sobre la democracia, si limitada o ilimitada, ha salpicado a muchos liberales contemporáneos de simpatías autoritarias y los ha acercado excesivamente a la derecha política —opción que puede ser políticamente legítima, pero no conducente a una aceptación masiva del paradigma liberal—.

En el plano de los valores, el liberalismo de nuestros tiempos vive una tensión con las corrientes religiosas que han convergido a la tradición liberal, desde las cuales la defensa de los valores familiares, los desafíos modernos del divorcio y la homosexualidad, o problemas como el del aborto plantean puntos de vista no liberales. A veces sectores liberales mantienen convicciones religiosas o morales que mueven a impulsos favorables a la censura o a restricciones especiales a algunas libertades, lo que entra en contradicción con la defensa irrestricta de las libertades individuales y hasta de las libertades públicas. El tema de la droga está en el centro de esta problemática, y es tratado ampliamente por Vargas Llosa subrayando la ineficacia del enfoque de la política norteamericana ante el problema y su relación con el ahondamiento de sentimientos antinorteamericanos en Bolivia y otros países.

Muchos de esos temas constituyen hoy asuntos de interés público aislados unos de otros. Sin duda, desde un paradigma liberal puede haber una respuesta común a esos distintos temas. Pero muchísimas personas en el mundo demandan y esperan más libertad en unos ámbitos de la vida que en otros. La atomización del debate, sin pretensión de sostener siempre la superioridad del paradigma entero, puede contribuir más a aumentar los grados de libertad reales en el mundo real donde habitan las personas reales que la ideologización extrema de los debates.

\section{Hacia otro rumbo}

La propuesta de Vargas Llosa es concebir un cambio de rumbo. En el plano indicativo de cuáles son las cosas que deberían cambiar para facilitar el progreso de las sociedades latinoamericanas, es difícil no concordar con sus propuestas. Hay una dificultad, sin embargo, en el plano de las implica- 
ciones acerca de qué hay que hacer para que esos cambios comiencen a ocurrir.

Los argumentos son sólidos cuando se los aplica a casos extremos de estatismo, corporativismo y prebendismo, tan acentuados en América Latina. Los encuentro más débiles cuando intento aplicarlos a los países capitalistas desarrollados, donde esas condiciones también existen, si bien en menor grado - y por cierto en grado diverso según los países- . Ahora bien, si buena parte del mundo que funciona más o menos bien padece en alguna medida el efecto de esas condiciones adversas a un capitalismo liberal, cabe concluir que la respuesta a los problemas de América Latina debería ser planteada en términos de avances graduales más que de un modelo alternativo.

De hecho, Europa y los Estados Unidos avanzaron hacia el capitalismo liberal en forma gradual. Tan gradual que sus economías no son enteramente liberales: no pocos sectores de la economía continúan siendo altamente proteccionistas, en otros se mantienen estructuras corporativistas y privilegios diversos y en algunos casos el estado continúa siendo un actor económico hiperactivo.

El capítulo final del libro aboga por cambios profundos, pero no propone un modelo bien delineado. Vargas Llosa enuncia, sin profundizarlos, algunos aspectos centrales de las reformas que propone: menos impuestos (soslaya una justificación de fondo de su preferencia por el impuesto a las ventas sobre el impuesto a las rentas, sin ninguna referencia al impuesto al patrimonio), menos regulaciones burocráticas que tornan muy altos los costos de entrada a los mercados y un sistema judicial con efectiva capacidad de administrar justicia. Para la transición a un orden de libertad aboga, sensiblemente, por un “aterrizaje suave”, esto es, se muestra gradualista en lo que concierne al pasaje a un nuevo orden.

No me resulta claro si está igualmente dispuesto a aceptar un gradualismo de fines. De hecho, una baja de impuestos y menos regulaciones estatales, menores costos de entrada establecidos burocráticamente coexisten, en algunos países hoy exitosos, con grados relativamente altos de intervención del estado en otras esferas. Lo mismo puede decirse de la educación. Personalmente encuentro difícil concebir, en el mundo que conozco y en el que imagino, un sistema de educación sin un fuerte componente de gasto público — que siempre, por definición, es expropiatorio-, pero reconozco casos en los que el componente de subsidio a la educación busca maximizar tanto la libertad individual de elegir como la distribución igualitaria de oportunidades. Ahora bien, un sistema educativo menos intervencionista no es necesariamente excluyente de un estado bastante más que mínimo en otras esferas. 
Al término del recorrido que propone Vargas Llosa nos encontramos con tres posibles vías alternativas para avanzar hacia la superación del orden vigente —orden cuyo fracaso está fuera de discusión-:

a) Una vía gradualista, incremental. Para impulsar un avance por un camino de esas características se requiere entrar a la actividad política y negociar cada avance, paso a paso y día a día, formando coaliciones con sectores económicos y ciudadanos interesados en algunas reformas. Es una lucha dura, que exige dosis altas de convicciones, capacidad política y sabiduría técnica, ya que es previsible que desde la sociedad se seguirá demandando del estado más que las esenciales funciones mínimas de defensa, cumplimiento de la ley y administración de justicia. Tales demandas no sólo provendrán de grupos con intereses creados contrarios a los cambios sino también de sectores que simplemente no creen que con menos estado estarán mejor.

b) Una vía de lucha de ideas, apuntando a la persuasión de las conciencias a través de la prédica, el debate y el análisis de los problemas. Este camino supone un desafío fascinante. Cuenta con la ventaja de lo apasionante que resulta al espíritu humano confrontar ideas; la desventaja es que raras veces el mundo cambió por esta vía sola.

c) Lograr el poder necesario para imponer otro orden. Esta vía, habitualmente llamada revolucionaria, me parece inconsistente con gran parte de los principios de la libertad del individuo. Creo que Vargas Llosa comparte este juicio.

El debate de ideas que Liberty for Latin America provoca será un estímulo en dos frentes de ideas que me parecen igualmente importantes para cambiar nuestras realidades: el de quienes se sienten identificados con la tradición del pensamiento liberal y el de quienes no lo están pero comparten las preocupaciones por el destino de estas sociedades. Alimentando a las elites con reflexiones sobre el mundo en el que actúan y estimulándolas a exponerse al debate de ideas, se aporta en las dos vías que veo están abiertas: el gradualismo político y el esclarecimiento intelectual. En ambos planos, este libro es bienvenido. 